\title{
TIME'S UP for Hospital Medicine
}

\author{
Dara Kass, MD*; Rhonda Graves Acholonu, MD²
}

'Department of Emergency Medicine, Columbia University Vagelos School of Medicine, New York, New York; ${ }^{2}$ Department of Pediatrics, Division of Hospital Medicine, Albert Einstein College of Medicine, Bronx, New York.

"If it is true that the full humanity of women is not our culture, then we can and must make it our culture."

\section{-Chimamanda Ngozi Adichie}

A young boy is on the way home from soccer when a driver hits his car head-on. His father dies immediately, but the boy survives. The boy is transported to the hospital and immediately rushed into the OR. The surgeon takes one look at him and says, "I can't operate on this patient. He's my son!" The riddle asks: If the father is dead, who is the surgeon?

Struggling to realize that the surgeon is a mom highlights the depth of gender bias in medicine. Gender bias leads to inequities which are magnified when compounded with differences in race, ethnicity, sexual orientation, gender identity and/or socioeconomic status. The recent National Academies report described the toll of gender inequities, including sexual harassment, and their impact on women in medicine. ${ }^{1}$ But like this riddle, the focus was directed towards those at the top of the hierarchy: physicians. It is undeniable that women physicians suffer the effects of inequities, but why exclude other women in healthcare? For example, over $90 \%$ of nurses are female, yet male nurses make higher salaries with lower degrees. ${ }^{2}$ If we only focus on physicians, we risk ignoring a problem faced by the entirety of our workforce.

Healthcare is a team sport. The practice of hospital medicine is a prime example of how each team member brings critical value. One would never be able to run an effective code without excellent nursing or successfully intubate a patient without a skilled respiratory therapist. Yet, when it comes to conversations about gender bias and sexual harassment, we rarely work together. The work of equity in healthcare must therefore become more like a lattice than a ladder, with many of us advocating for or with one another.

As hospital medicine has grown, hospitalists have become genuine agents of change. Therefore, this change too, must begin with hospitalists. As leaders in healthcare, we must advocate for equity for all, from the lab technician to the CEO.

*Corresponding Author: Dara Kass, MD; dak2169@cumc.columbia.edu

Received: March 29, 2019; Accepted: March 31, 2019

๑) 2019 Society of Hospital Medicine DOI 10.12788/jhm.3216
We must engage and respond when direct care workers (often minorities), face gender or racial bias. In short, if we see something, we must say something.

To create a culture of inclusivity and intersectionality in healthcare, we suggest the following:

- Unite healthcare workers across fields. View your fellow healthcare worker as a team member, not as a subordinate or ancillary staff. Ask them what their experiences regarding inequity have been. See things from their perspective.

- Be a champion for those affected by harassment and inequity. Offer direct support to anyone affected by harassment or inequity. Accompany them to human resources or use your influence to advocate for gender-based salary audits.

- Raise awareness and knowledge. Know the resources in your institution and share them with others. Encourage teams to discuss the impact of microaggressions and implicit bias together as opposed to in role-specific groups. Use communication to lend allyship and support. If you see microaggressions based on gender or race, inquire by asking "I'm curious... why would you say that?" or share the impact a statement has on you by noting "The comment doesn't just affect one person, it affects all of us."

People create culture. Meaningful cultural change must be inclusive and intersectional. Historically, movements focused on equity have failed to be inclusive, leading to certain groups feeling marginalized. The time has come to affect change in healthcare across all differences. Whether in the role of physician, nurse, advanced practice provider, or paramedical staff, it's time to stand together and say: "time is up."

Disclosures: Dr Kass and Dr. Acholonu are founding members of TIME'S UP Healthcare

\section{References}

1. National Academies of Sciences, Engineering, and Medicine. Sexual harassment of women: climate, culture, and consequences in academic sciences, engineering, and medicine. Washington, DC: National Academies Press, August 2018. (https://www.nap.edu/catalog/24994/sexual-harassment-of-women-climate-culture-and-consequences-in-academic). Accessed March 1, 2019.

2. 2018 Nurse.com. Nursing Salary Research Report. http://mediakit.nurse. com/wp-content/uploads/2018/06/2018-Nurse.com-Salary-Research-Report.pdf. Accessed March 1, 2019. 